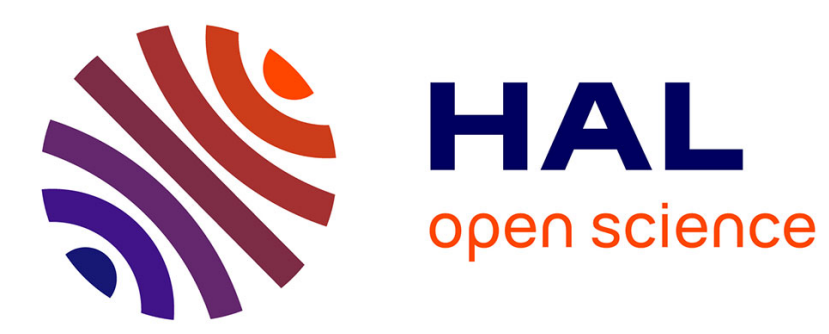

\title{
Polypyridyl-based $\mathrm{Cu}(\mathrm{II})$ coordination polymers: Synthesis, structural and magnetic characterizations \\ Karine Déniel, Kahina Nebbali, Nathalie Cosquer, Françoise Conan, Carlos J \\ Gómez-García, Said Yefsah, Smail Triki
}

\section{- To cite this version:}

Karine Déniel, Kahina Nebbali, Nathalie Cosquer, Françoise Conan, Carlos J Gómez-García, et al.. Polypyridyl-based $\mathrm{Cu}(\mathrm{II})$ coordination polymers: Synthesis, structural and magnetic characterizations. Polyhedron, 2015, 97, pp.253-259. 10.1016/j.poly.2015.05.032 . hal-01532319

\section{HAL Id: hal-01532319 \\ https://hal.univ-brest.fr/hal-01532319}

Submitted on 2 Jun 2017

HAL is a multi-disciplinary open access archive for the deposit and dissemination of scientific research documents, whether they are published or not. The documents may come from teaching and research institutions in France or abroad, or from public or private research centers.
L'archive ouverte pluridisciplinaire HAL, est destinée au dépôt et à la diffusion de documents scientifiques de niveau recherche, publiés ou non, émanant des établissements d'enseignement et de recherche français ou étrangers, des laboratoires publics ou privés. 


\title{
Polypyridyl-based $\mathrm{Cu}(\mathrm{II})$ coordination polymers: synthesis, structural and magnetic characterizations.
}

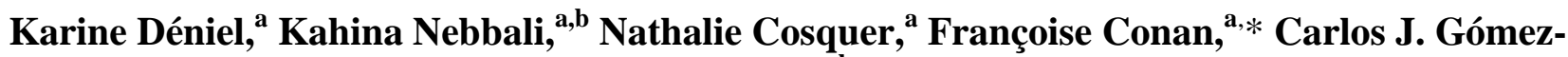 \\ García, ${ }^{\mathrm{c}}$ Said Yefsah, ${ }^{\mathrm{b}}$ Smail Triki ${ }^{\mathrm{a}, *}$
}

${ }^{a}$ UMR CNRS 6521, Chimie, Electrochimie Moléculaires, Chimie Analytique, Université de Bretagne Occidentale, BP 809, 29285 Brest Cedex, France.

*Corresponding authors: Francoise.Conan@univ-brest.fr, $\underline{\text { Smail.Triki@ univ-brest.fr }}$

${ }^{\mathrm{b}}$ Faculté des Sciences, Université Mouloud Mammeri, Tizi-Ouzou, Algérie.

${ }^{\mathrm{c}}$ Instituto de Ciencia Molecular (ICMol), Universidad de Valencia, C/ Catedrático José Beltrán, 2, 46980 Paterna, Valencia, Spain.

Keywords: polypyridyl ligands / cyanocarbanion ligands / copper complexes / coordination polymers

\begin{abstract}
New $\mathrm{Cu}(\mathrm{II})$ coordination polymeric neutral chains of formula $\left.\left[\mathrm{Cu}_{2}(1,4-\mathrm{tpbd}) \mathrm{Cl}_{2} \mathrm{~L}_{2}\right)\right]$ (1,4-tpbd $=\quad N, N, N^{\prime} N^{\prime}$-tetrakis(2-pyridylmethyl)benzene-1,4-diamine, $\quad \mathrm{L} \quad=\quad$ 1,1,3,3-tetracyano-2ethoxypropenide (tcnoet) ${ }^{-}$(1) or 1,1,3,3-tetracyano-2-propoxypropenide (tcnopr) ${ }^{-}$(2)) have been synthesized and characterized by infrared spectroscopy, X-ray diffraction and magnetic measurements. The crystal structure determinations of $\mathbf{1}$ and $\mathbf{2}$ reveal in both cases a one-dimensional structure in which the 1,4-tpbd acts as a bis-chelating ligand and the two chloride anions as asymmetrical bridging ligands. The $\mathrm{Cu} \cdots \mathrm{Cu}$ distances through the bis-chelating 1,4-tpbd ligand (8.194(1) and 8.245(3) $\AA$ for $\mathbf{1}$ and $\mathbf{2}$ respectively) are in the range of the corresponding distances observed for parent complexes involving similar bridges; and as expected, the $\mathrm{Cu} \cdots \mathrm{Cu}$ distances through the asymmetrical $\left(\mu_{2}-\mathrm{Cl}\right)_{2}$ bridges are significantly shorter $(4.021(2)$ and $4.125(2) \AA$ for $\mathbf{1}$ and $\mathbf{2}$, respectively). For both compounds, magnetic measurements exhibit a maximum in the $\chi_{m} v s . T$ plot (at $50 \mathrm{~K}$ for $\mathbf{1}$, and at $48 \mathrm{~K}$ for 2 ), characteristic of antiferromagnetic exchange interactions occurring mainly through the tbpd organic ligand that can be very well reproduced with a $S=1 / 2$ dimer model with $\mathrm{g}=2.114, \mathrm{~J}=-41.2 \mathrm{~cm}^{-1}$ for $\mathbf{1}$ and $\mathrm{g}=2.105$ and $\mathrm{J}=-39.3 \mathrm{~cm}^{-1}$ for 2 .
\end{abstract}




\section{Introduction}

For many years, with the main purpose to prepare new molecular materials, our group has developed the coordination chemistry of polynitrile anions and especially cyanocarbanion species (Scheme 1) which have been evidenced as fascinating ligands for the preparation of various "M(II)/cyanocarbanion" binary systems from discrete to polymeric systems [1-6]. Taking into account the crucial role of these anionic ligands, we are interested in using them in combination with other chelating or bridging neutral co-ligands such as the aromatic $\mathrm{N}$-containing ligands to explore the role of their structural and electronic characteristics in the field of molecular materials including switchable materials exhibiting magnetic bistability [7-13], as in the intriguing derivative $\left[\mathrm{Cu}(\right.$ bpym $\left.)(\text { tcnoet })_{2}\right] \cdot \mathrm{H}_{2} \mathrm{O} \quad$ (bpym $=2,2^{\prime}$-bipyrimidine; $\quad(\text { tcnoet })^{-}=1,1,3,3$-tetracyano-2ethoxypropenide) that displays a zigzag infinite chain with an unusual magnetic transition and reversible thermochromism [13]. Experimental and theoretical studies revealed that both magnetic and thermochromic transitions are induced by several structural and electronic effects such as the flexibility of the cyanocarbanion ligand, the rigidity and the bis-chelating coordination mode of the bpym ligand and the dynamic Jahn-Teller effect of the $\mathrm{Cu}$ (II) metal ion. In this context, we have decided to extend this system to other rigid bridging ligands such as the tetra- $\mathrm{N}$-functionalized $p$ phenylenediamine co-ligands acting with a bis(tridentate) bridging coordination mode [14] (Scheme 1). As the 2,2'-bpym ligand, it has been clearly established that such rigid hexadentate bridging coligand, owing to its specific electronic and structural features, could be a suitable building block for the design of various co-ordination derivatives, from mononuclear to extended molecular systems [14-17]. Furthermore, such derivatives could find applications in the bioinorganic chemistry field as exemplified by the copper(II) complexes based on the 1,4-tpbd ligand $\left(N, N, N^{\prime} N^{\prime}\right.$ '-tetrakis(2pyridylmethyl)benzene-1,4-diamine) which have recently been investigated for their DNA cleavage properties [18-19].

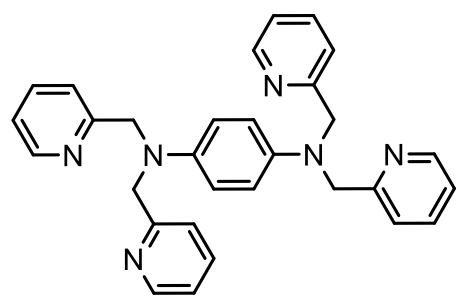

$1,4-$ tpbd<smiles>CCOC(C(C)=N)C(C)=N</smiles>

(tcnoet) $)^{-}$<smiles>C=C(C#N)C(OCCO)C(C#N)C#N</smiles>

(tcnopr) $)^{-}$

Scheme 1 
In this work, we report the syntheses, structural characterizations and magnetic properties of two new copper coordination polymers formulated as $\left.\left[\mathrm{Cu}_{2}(1,4-\mathrm{tpbd}) \mathrm{Cl}_{2} \mathrm{~L}_{2}\right)\right]$ with $\mathrm{L}=$ tcnoet $^{-}(\mathbf{1})$ and tcnopr $^{-}(2)$, based on the 1,4-tpbd molecule and organocyanide anions (Scheme 1).

\section{Experimental}

\subsection{Reagents and techniques}

Tetracyanoethylene, urea, potassium terbutoxide $\left(\mathrm{C}_{4} \mathrm{H}_{9} \mathrm{OK}\right)$, malononitrile $\left(\mathrm{CH}_{2}(\mathrm{CN})_{2}\right)$, pphenylenediamine, 2-(picolyl)chloride hydrochloride, tetramethylorthosilicate (TMOS) and $\mathrm{CuCl}_{2} \cdot 2 \mathrm{H}_{2} \mathrm{O}$ were purchased from Sigma-Aldrich and used without further purification. Solvents were used and purified by standard procedures. The $N, N, N^{\prime} N^{\prime}$-tetrakis(2-pyridylmethyl)benzene-1,4diamine (1,4-tpbd) was prepared following the procedure described in reference [14]. Elemental analyses were performed by the "Service Central d'Analyses du CNRS", Gif-sur-Yvette, France. Infrared spectra were recorded in the range $4000-50 \mathrm{~cm}^{-1}$ on a FT-IR Brucker ATR Vertex 70 Spectrometer. Diffraction analyses were performed using an Oxford Diffraction Xcalibur $\kappa-C C D$ diffractometer. NMR spectra were recorded on a Brucker DRX 300 or Brucker Avance 400 and 500 MHz. Magnetic measurements were performed with a Quantum Design MPMS-XL-5 SQUID magnetometer in the 2-300 $\mathrm{K}$ temperature range with an applied magnetic field of $0.1 \mathrm{~T}$ on polycrystalline samples of compounds 1 and $\mathbf{2}$ (with masses of 2.00 and $13.37 \mathrm{mg}$, respectively). The susceptibility data were corrected for the sample holders previously measured under the same conditions, and for the diamagnetic contributions as deduced by using Pascal's constant tables $\left(\chi_{\text {dia }}=-547.4 \times 10^{-6}\right.$ and $-571.6 \times 10^{-6}$ emu. $\mathrm{mol}^{-1}$ for $\mathbf{1}$ and 2 , respectively) [20].

\subsection{Preparations}

\subsubsection{Synthesis of the potassium cyanocarbanion salts.}

The potassium salt of 1,1,3,3-tetracyano-2-ethoxypropenide, $\mathrm{K}$ (tcnoet) was synthesized according to reference [3]. Anal. Calcd. for $\mathrm{KC}_{9} \mathrm{H}_{5} \mathrm{~N}_{4} \mathrm{O}: \mathrm{C}, 48.2 ; \mathrm{N}, 25.0 ; \mathrm{H}, 2.3 \%$. Found: C, 47.9; $\mathrm{N}, 25.3 ; \mathrm{H}, 2.2$. IR data $\left(\mathrm{v} / \mathrm{cm}^{-1}\right)$ for K(tcnoet): 2998(w), 2986(w), 2940(w), 2225(w), 2196(s), 2164(m), 2149(m), 1488(s), 1444(m), 1422(s), 1377(s), 1345(s), 1281(w), 1260(w), 1228(m), 1177(s), 1140(m), 1101(m), 996(s), 915(w), 847(m), 707(m), 618(w), 568(m), 539(s), 490(m), 472(s), 414(w). NMR ${ }^{1} \mathrm{H}\left(\mathrm{D}_{2} \mathrm{O}, 300 \mathrm{MHz}\right): 1.38\left(\mathrm{t}, 3 \mathrm{H},{ }^{3} \mathrm{~J}_{\mathrm{H}-\mathrm{H}}=7.1 \mathrm{~Hz}, \mathrm{CH}_{3}\right), 4.42\left(\mathrm{q}, 2 \mathrm{H},{ }^{3} \mathrm{~J}_{\mathrm{H}-\mathrm{H}}=\right.$ 7.1Hz, $\left.\mathrm{CH}_{2}\right) . \mathrm{NMR}{ }^{13} \mathrm{C}\left(\mathrm{D}_{2} \mathrm{O}, 125 \mathrm{MHz}, 25^{\circ} \mathrm{C}\right): 17.50\left(-\mathrm{CH}_{3}\right), 49.15\left(-\mathrm{C}(\mathrm{CN})_{2}\right), 75.37\left(-\mathrm{CH}_{2}\right)$, $121.11(-\mathrm{CN}), \quad 186.37 \quad\left(-\mathrm{O}-\mathrm{C}\left(\mathrm{C}(\mathrm{CN})_{2}\right)_{2}\right)$. The potassium salt of 1,1,3,3-tetracyano-2propoxypropenide, $\mathrm{K}$ (tcnopr) was prepared with the following procedure: tetracyanoethylene (3.2 $\mathrm{g}$, $25 \mathrm{mmol})$ and urea $(1.5 \mathrm{~g}, 25 \mathrm{mmol})$ were dissolved in $40 \mathrm{~mL}$ of propan-1-ol and warmed to $25^{\circ} \mathrm{C}$ during 4 hours. Solvent was removed under vacuum and the solid was extracted with $20 \mathrm{~mL}$ of a 1:1 
water/diethyl ether mixture. The aqueous phase was extracted two more times with $20 \mathrm{~mL}$ of diethyl ether. The organic fraction was dried $\left(\mathrm{MgSO}_{4}\right)$ and the solvent removed to give the 1,1-dicyano-2,2dipropanoethylene as a yellow oil. (3.28 g; $67 \%)$. IR data $\left(\mathrm{v} / \mathrm{cm}^{-1}\right): 2973(\mathrm{~s}), 2928(\mathrm{~m}), 2882(\mathrm{~m})$, 2229(w), 2216(w), 2206(w), 2174(w), 1747 (w), 1729 (w), 1642(w), 1551(m), 1380(m), 1324(s), 1271(w), 1174(w), 1087(s), 1045(s), 880(s), 801(w), 825 (m), 430(m). The yellow oil of 1,1-dicyano2,2-dipropanoethylene $(2.90 \mathrm{~g}, 15 \mathrm{mmol})$ was dissolved in $40 \mathrm{~mL}$ of EtOH and a mixture of $\mathrm{CH}_{2}(\mathrm{CN})_{2}(1.00 \mathrm{~g}, 15 \mathrm{mmol})$ and tBuOK $(1.67 \mathrm{~g}, 15 \mathrm{mmol})$ in $\mathrm{EtOH}(40 \mathrm{~mL})$ was poured on it. The resultant solution was stirred under reflux for 2 hours, and allowed to cool before being placed in a freezer to obtain K(tcnopr) as an orange powder. (2.45 g, $69 \%)$. IR data (v/cm $\left.{ }^{-1}\right): 2973(w), 2942(w)$, 2929(w), 2881(w), 2224(w), 2198(s), 2152(m), 1482(s), 1430(s), 1382(m), 1364(s), 1348(s), 1275(w), 1252(w), 1225(w), 1178(s), 1144(w), 1046(m), 930(s), 896(m), 860(m), 707(m), 623(w), 571(w), 540(s), 477(m). NMR ${ }^{1} \mathrm{H}\left(300 \mathrm{MHz}, \mathrm{D}_{2} \mathrm{O}\right): 1.00\left(\mathrm{t}, 3 \mathrm{H}, \mathrm{J}=7.42 \mathrm{~Hz}, \mathrm{CH}_{3}\right) ; 1.77(\mathrm{~m}, 2 \mathrm{H}$, $\left.\mathrm{CH}_{2}\right) ; 4.35\left(\mathrm{t}, 2 \mathrm{H}, \mathrm{J}=6.35 \mathrm{~Hz}, \mathrm{CH}_{2} \mathrm{O}\right) . \mathrm{NMR}{ }^{13} \mathrm{C}\left(125 \mathrm{MHz}, \mathrm{D}_{2} \mathrm{O}\right): 12.37\left(-\mathrm{CH}_{3}\right), 25.64\left(-\mathrm{CH}_{2}-\mathrm{CH}_{3}\right)$, $48.75\left(-\mathbf{C}(\mathrm{CN})_{2}\right), 80.80\left(-\mathrm{CH}_{2}-\mathrm{O}-\right), 121.17(-\mathrm{CN}), 186.62\left(-\mathrm{O}-\mathrm{C}\left(\mathrm{C}(\mathrm{CN})_{2}\right)_{2}\right)$.

\subsubsection{Synthesis of the Cu complexes (1 and 2 ).}

Both complexes were prepared using a similar procedure: Salts of cyanocarbanion (Ktcnoet or Ktcnopr, $0.24 \mathrm{mmol})$ and $\mathrm{CuCl}_{2} \cdot 2 \mathrm{H}_{2} \mathrm{O}(20 \mathrm{mg}, 0.12 \mathrm{mmol})$ were dissolved in $9 \mathrm{~mL}$ of water. Then, 1 $\mathrm{mL}$ of TMOS was added and the mixture was stirred for obtaining a full homogenization of the mixture. Few hours later, the gel was formed and a solution of tpbd $(28 \mathrm{mg}, 0.06 \mathrm{mmol})$ in $\mathrm{CH}_{3} \mathrm{CN}$ $(10 \mathrm{~mL})$ was slowly poured on it. Dark green prismatic single crystals appear in the top of the gel after 4 or 5 days. Crystals were separated from the gel under the microscope. [ $\mathrm{Cu}_{2}(1,4-$ tpbd) $\mathrm{Cl}_{2}$ (tcnoet) $)_{2}$ (1). Yield: $20 \mathrm{mg}(33 \%)$. Elemental analysis data: calculated. (\%) for $\mathrm{C}_{48} \mathrm{H}_{38} \mathrm{O}_{2} \mathrm{~N}_{14} \mathrm{Cu}_{2} \mathrm{Cl}_{2}(1040.93 \mathrm{~g} / \mathrm{mol}): \mathrm{C}, 55.39 ; \mathrm{H}, 3.68 ; \mathrm{N}, 18.84$. Found (\%): C, 55.27; H, 3.68; N, 18.74. IR data $\left(\mathrm{v} / \mathrm{cm}^{-1}\right)$ : 3095(w), 2981(w), 2220(w), 2197(s), 2144(w), 1610(m), 1575(w), 1514(m), 1487(s), 1445(s), 1407(m), 1379(m), 1344(s), 1322(m), 1285(m), 1244(w), 1227(w), 1192(m), 1174(s), 1155(m), 1145(m), 1116(w), 1094(m), 1055(m), 1032(m), 998(s), 965(m), 899(m), 854(m), 829(s), 787(s), 777(s), 744(m), 715(m), 678(m), 654(m), 632(w), 610(w), 568(m), 537(m), 493(w), 480(m), 469(m), 425(m), 419(m), 314(m), 292(s), 283(s), 246(w), 208(s), 160(s), 143(s), 103(m), 86(s). [ $\mathrm{Cu}_{2}(1,4-\mathrm{tpbd}) \mathrm{Cl}_{2}$ (tcnopr) $)_{2}$ (2). Yield: $45 \mathrm{mg}$ (71\%). Elemental analysis data: calculated. (\%) for $\mathrm{C}_{50} \mathrm{H}_{42} \mathrm{O}_{2} \mathrm{~N}_{14} \mathrm{Cu}_{2} \mathrm{Cl}_{2}(1068.98 \mathrm{~g} / \mathrm{mol})$ : C, 56.18; H, 3.96; N, 18.34. Found (\%): C, 56.26; H, 3.95; $\mathrm{N}, 18.31$. IR data $\left(\mathrm{v} / \mathrm{cm}^{-1}\right):$ 3089(w), 2956(w), 2216(vw), 2196(s), $2149(\mathrm{vw}), 1610(\mathrm{~m}), 1574(\mathrm{w})$, 1515(m), 1482(s), 1446(s), 1410(m), 1379(m), 1356(m), 1333(m), 1323(m), 1286(m), 1249(w), 1227(w), 1192(m), 1165(s), 1114(w), 1092(m), 1055(m), 1032(m), 1000(w), 980(w), 965(m), 
950(m), 931(m), 899(m), 863(m), 830(m), 785(s), 744(m), 715(m), 678(m), 654(m), 633(m), 569(m), 538(m), 494(w), 480(m), 468(m), 427(m), 418(m), $352(\mathrm{w}), 314(\mathrm{~m}), 295(\mathrm{~s}), 283(\mathrm{~s}), 246(\mathrm{w}), 207(\mathrm{~s})$, 160(s), 143(s), 108(m), 86(s).

\subsection{X-ray crystallography}

Single crystal X-ray data for compounds 1 and 2 were collected at $T=296 \mathrm{~K}$ on an Oxford Diffraction Xcalibur $\kappa$-CCD diffractometer, using a graphite monochromated Mo-K $\alpha$ radiation $(\lambda=$ $0.71073 \AA$ ). Data collection and data reduction were done with the CRYSALIS-CCD and CRYSALIS-RED programs [21]. The crystal structures were solved by direct methods and successive Fourier difference syntheses, and were refined on $F^{2}$ by weighted anisotropic full-matrix least-square methods [22]. All non-hydrogen atoms were refined anisotropically while the hydrogen atoms were calculated and therefore included as isotropic fixed contributors to $F_{\mathrm{c}}$. All other calculations were performed with standard procedures (WINGX) [23]. Scattering factors and corrections for anomalous dispersion were taken from the International tables for X-ray crystallography [24]. The thermal ellipsoid drawings were performed using the ORTEP [25]. Pertinent crystal data and selected bond distances and bond angles are listed in tables 1 and 2.

\section{Results and discussion}

Both derivatives $\mathbf{1}$ and $\mathbf{2}$ have been synthesized according to a sol-gel procedure using tetramethylorthosilicate (TMOS) as the gel-forming reagent, by slow diffusion of an acetonitrile solution of the organic molecule 1,4-tpbd into a freshly prepared gel obtained by mixing aqueous solutions of the organocyanide anions, copper (II) chloride and TMOS. After few days, suitable crystals for X-ray studies were obtained and analyzed as $\left[\mathrm{Cu}_{2}(1,4-\mathrm{tpbd}) \mathrm{Cl}_{2}(\text { tcnoet })_{2}\right]$ for $\mathbf{1}$ and $\left[\mathrm{Cu}_{2}(1,4-\mathrm{tpbd}) \mathrm{Cl}_{2}(\text { tcnopr })_{2}\right]$ for 2 . Both compounds display similar infrared spectra patterns in the region ascribable to the vibration of the $\mathrm{CN}$ bonds i.e. a strong absorption band at 2197 and 2196 $\mathrm{cm}^{-1}$ for $\mathbf{1}$ and $\mathbf{2}$ respectively, together with two smaller narrow bands (2220 and $2145 \mathrm{~cm}^{-1}$ for 1; 2216 and $2149 \mathrm{~cm}^{-1}$ for 2 ). These values are nearly similar to those observed for the corresponding potassium salts (K(tcnoet): 2225(w), 2196(s), 2164(m), 2149(m) and K(tcnopr): 2224(w), 2198(s), 2152(m)) containing the non coordinated cyanocarbanion moieties, and consequently do not allow any discussion about the coordination of some $\mathrm{CN}$ groups for both compounds. Considering the tpbd features, it is worth to note that the absorption band, at almost $1610 \mathrm{~cm}^{-1}$, is slightly shifted towards higher wave numbers with respect to the free ligand, indicative of the coordination of the ligand to the metal centre in both derivatives [18]. Besides, there are two bands at 293 and $246 \mathrm{~cm}^{-1}$, ascribable to the $\mathrm{Cu}-\mathrm{Cl}$ vibrations, which are similar to those observed in the $\left[\mathrm{CuCl}_{2}(\mathrm{py})_{2}\right]$ complex [26].

The crystal structures of $\mathbf{1}$ and $\mathbf{2}$ have been determined at room temperature. Both derivatives 
crystallize in the $P-1$ triclinic space group (Table 1 ). 
Table 1

Crystal data and structural refinement parameters for compounds 1-2

\begin{tabular}{|c|c|c|}
\hline & 1 & 2 \\
\hline${ }^{\mathrm{a}}$ Empirical formula & $\mathrm{C}_{48} \mathrm{H}_{38} \mathrm{Cl}_{2} \mathrm{Cu}_{2} \mathrm{~N}_{14} \mathrm{O}_{2}$ & $\mathrm{C}_{50} \mathrm{H}_{42} \mathrm{Cl}_{2} \mathrm{Cu}_{2} \mathrm{~N}_{14} \mathrm{O}_{2}$ \\
\hline Molecular weight & 1040.90 & 1068.96 \\
\hline Temperature (K) & 296 & 296 \\
\hline Space group & $P-1$ & $P-1$ \\
\hline$a(\AA)$ & $8.5870(4)$ & $8.892(3)$ \\
\hline$b(\AA)$ & $12.0710(7)$ & $12.189(4)$ \\
\hline$c(\AA)$ & $12.3607(7)$ & $12.203(4)$ \\
\hline$\alpha\left(^{\circ}\right)$ & $112.933(5)$ & $113.82(3)$ \\
\hline$\beta\left(^{\circ}\right)$ & $101.275(4)$ & $101.72(2)$ \\
\hline$\gamma\left({ }^{\circ}\right)$ & $92.431(4)$ & $93.51(2)$ \\
\hline$V\left(\AA^{3}\right)$ & $1147.17(11)$ & $1169.4(6)$ \\
\hline${ }^{\mathrm{a}} Z$ & 1 & 1 \\
\hline$\rho_{\text {calc }}\left(\right.$ g.cm $\left.{ }^{-3}\right)$ & 1.507 & 1.518 \\
\hline$\mu\left(\mathrm{mm}^{-1}\right)$ & 1.101 & 1.082 \\
\hline$F(000)$ & 532 & 548 \\
\hline Crystal size (mm) & $0.25 \times 0.08 \times 0.07$ & $0.17 \times 0.11 \times 0.08$ \\
\hline Refl. measured & 8931 & 8940 \\
\hline $2 \theta$ range $\left(^{\circ}\right)$ & $3.09-26.37$ & $3.36-26.37$ \\
\hline Refl. unique / $R_{\text {int }}$ & $4664 / 0.0321$ & 4749 / 0.1221 \\
\hline Refl. with I>2 $\sigma(I)$ & 3171 & 2635 \\
\hline$N_{v}$ & 308 & 316 \\
\hline${ }^{\mathrm{b}} R 1 /{ }^{\mathrm{c}} w R 2$ & $0.0408 / 0.0952$ & $0.0765 / 0.2310$ \\
\hline${ }^{\mathrm{d}}$ GooF & 0.949 & 0.960 \\
\hline$\Delta \rho_{\max , \min }\left(\mathrm{e}^{-3}\right)$ & $+0.384 /-0.262$ & $+0.773 /-0.786$ \\
\hline
\end{tabular}

${ }^{\mathrm{a}}$ The asymmetric unit contains 0.5 of the chemical formula

${ }^{\mathrm{b}} R I=\sum\left|F_{\mathrm{O}}-F_{\mathrm{c}}\right| / F_{\mathrm{o}}$.

${ }^{\mathrm{c}} w R 2=\left\{\Sigma\left[w\left(F_{o}^{2}-F_{c}^{2}\right)^{2}\right] / \Sigma\left[w\left(F_{o}^{2}\right)^{2}\right]\right\}^{1 / 2}$.

${ }^{\mathrm{d}} \mathrm{GooF}=\left\{\Sigma\left[w\left(F_{o}^{2}-F_{c}^{2}\right)^{2}\right] /\left(N_{\text {obs }}-N_{\text {var }}\right)\right\}^{1 / 2}$

The molecular structures are shown in Figure 1 and selected bond angles and lengths are gathered in Table 2. Careful examination of the structural features (Tables 1-2) points out that both compounds exhibit almost similar structures. The asymmetric unit displays one copper (II) ion, one organocyanide anion (tcnoet for $\mathbf{1}$, tcnopr ${ }^{-}$for $\mathbf{2}$ ) and one chlorine atom, all in general positions, and half tpbd molecule located on an inversion centre. The whole molecular structure is completed by symmetry and, accordingly, these compounds can be described as centro-symmetric dinuclear copper complexes (Figure 1). 


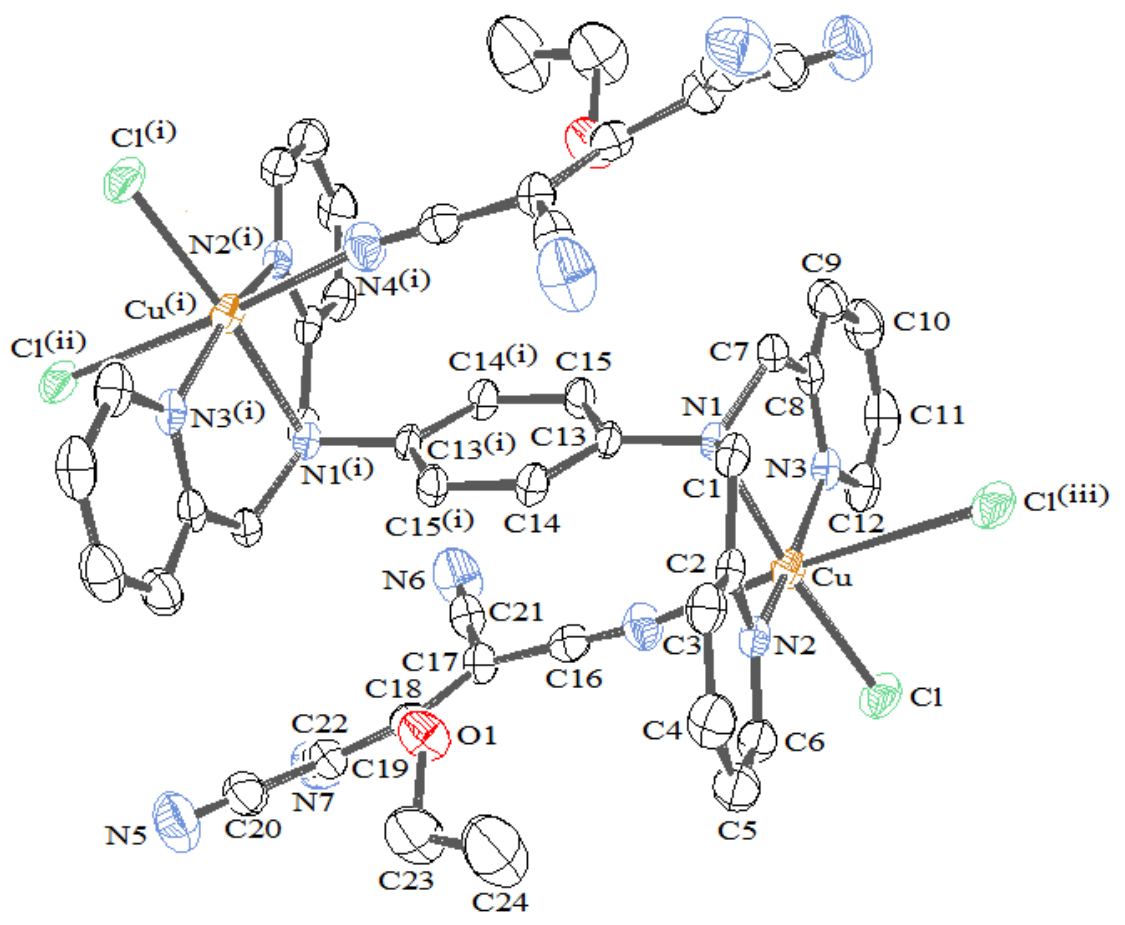

(a)

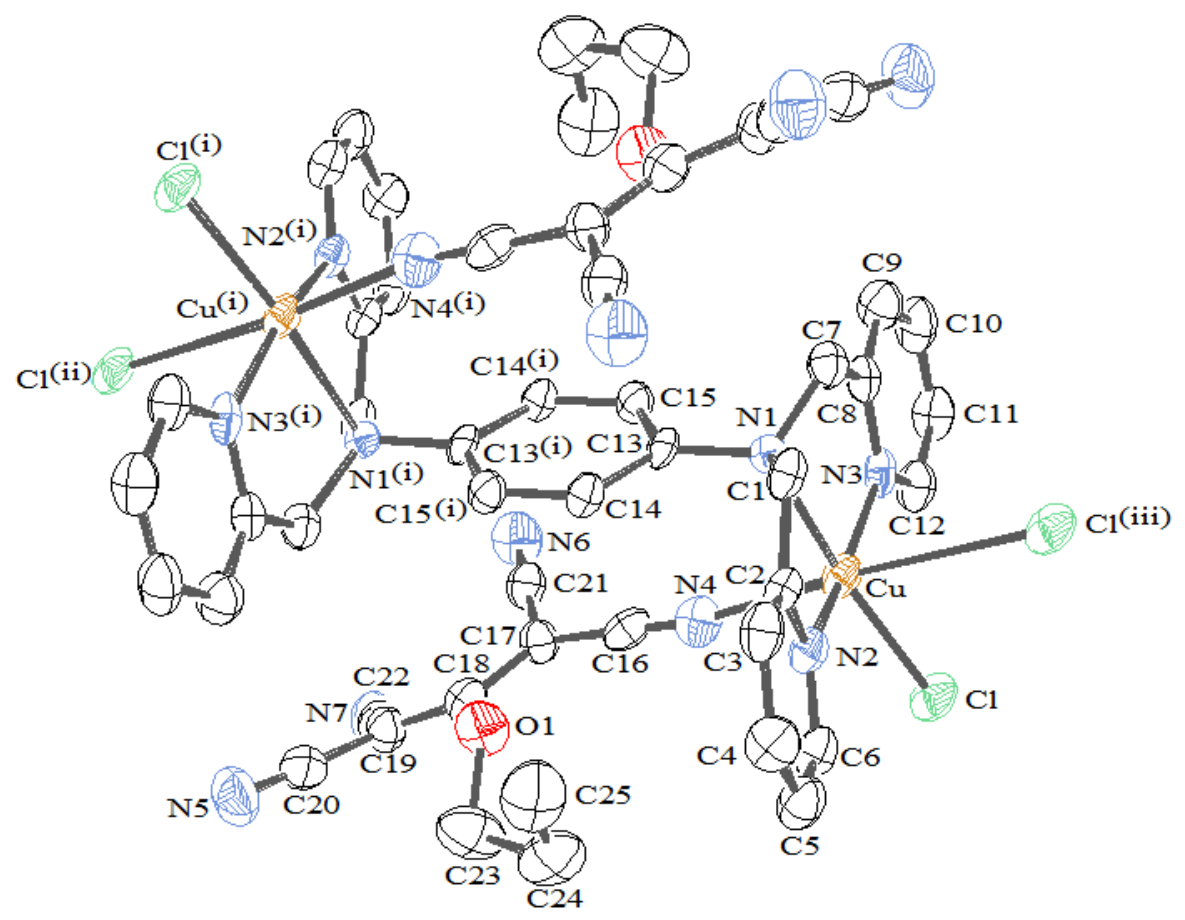

(b)

Figure 1. The thermal ellipsoid drawing [25] (40\% probability ellipsoids) of the molecular structures of 1 (a) and 2 (b) showing the labeling scheme of the asymmetric unit and some symmetrically equivalent atoms. Code for equivalent positions: (i) 1-x, 1-y, 1-z; (ii) 1-x, -y, 1-z; (iii) x, 1+y, z. 
The copper (II) ion is surrounded by three nitrogen atoms (N1, N2 and N3) arising from the 1,4-tpbd ligand and by a chlorine atom, according to a distorted square planar geometry with $\mathrm{Cu}-\mathrm{N}$ bond lengths in the range 1.975-2.143 $\AA$ and $\mathrm{Cu}-\mathrm{Cl}$ bond lengths close to $2.27 \AA(2.2709$ (8) $\AA$ for $\mathbf{1}$, 2.266(2) $\AA$ for 2). Despite the deviation from the theoretical value $\left(90^{\circ}\right)$ observed for the $\mathrm{N} 1-\mathrm{Cu}-\mathrm{N} 3$ and N2-Cu-N1 bond angles within this plane, due to constraints induced by the chelating ligand, the sum of the four $\mathrm{N}-\mathrm{Cu}-\mathrm{N}$ and $\mathrm{N}-\mathrm{Cu}-\mathrm{Cl}$ angles, close to $360^{\circ}$, traduces the quasi planarity of this $\mathrm{CuN}_{3} \mathrm{Cl}$ plane (maximum deviation from planarity being 0.135 and $0.138 \AA$ in $\mathbf{1}$ and 2 respectively). The copper atom is weakly bonded to a fourth nitrogen atom (N4) arising from the terminal organocyanide ligand that occupies an apical position. The $\mathrm{Cu}-\mathrm{N} 4$ bond length, which is noticeably longer than the equatorial ones (2.395(3) $\AA$ for 1 and 2.445(6) $\AA$ for 2), allows however the copper centre to extend its coordination number to 5 according to a distorted square planar pyramid $(\tau=0.19$ for both complexes) [27].

Table 2

Selected bond distances $(\AA)$ and bon angles $\left(^{\circ}\right)$ for $\mathbf{1 - 2}$

\begin{tabular}{lll}
\hline & \multicolumn{1}{c}{$\mathbf{1}$} & \multicolumn{1}{c}{$\mathbf{2}$} \\
\hline $\mathrm{N} 1-\mathrm{Cu}$ & $2.135(2)$ & $2.143(4)$ \\
$\mathrm{N} 2-\mathrm{Cu}$ & $1.975(2)$ & $1.981(4)$ \\
$\mathrm{N} 3-\mathrm{Cu}$ & $1.978(2)$ & $1.975(5)$ \\
$\mathrm{N} 4-\mathrm{Cu}$ & $2.395(3)$ & $2.445(6)$ \\
$\mathrm{Cu}-\mathrm{Cl}$ & $2.2709(8)$ & $2.2659(16)$ \\
$\mathrm{N} 2-\mathrm{Cu}-\mathrm{N} 3$ & $161.54(9)$ & $161.25(19)$ \\
$\mathrm{N} 2-\mathrm{Cu}-\mathrm{N} 1$ & $82.22(9)$ & $82.48(16)$ \\
$\mathrm{N} 3-\mathrm{Cu}-\mathrm{N} 1$ & $82.82(9)$ & $82.56(16)$ \\
$\mathrm{N} 2-\mathrm{Cu}-\mathrm{Cl}$ & $96.30(7)$ & $96.02(13)$ \\
$\mathrm{N} 3-\mathrm{Cu}-\mathrm{Cl}$ & $97.19(7)$ & $97.43(14)$ \\
$\mathrm{N} 1-\mathrm{Cu}-\mathrm{Cl}$ & $172.81(6)$ & $172.86(11)$ \\
$\mathrm{N} 2-\mathrm{Cu}-\mathrm{N} 4$ & $94.32(9)$ & $98.65(18)$ \\
$\mathrm{N} 3-\mathrm{Cu}-\mathrm{N} 4$ & $97.80(9)$ & $93.96(18)$ \\
$\mathrm{N} 1-\mathrm{Cu}-\mathrm{N} 4$ & $95.35(8)$ & $95.47(16)$ \\
$\mathrm{Cl}-\mathrm{Cu}-\mathrm{N} 4$ & $91.77(7)$ & $91.66(13)$ \\
\hline
\end{tabular}

Additionally, a very weak interaction occurs between the $\mathrm{Cu}$ (II) centre and the chlorine atom $\mathrm{Cl}^{(\mathrm{iii})}$ (Cu-Cl ${ }^{(\mathrm{iii})}$ distance: $3.1755(9) \AA$ for 1 and 3.293(2) $\AA$ for 2) and accordingly occupies the second apical position of the coordination sphere. This $\mathrm{Cu} \cdots \mathrm{Cl}$ interaction allows to view the $\mathrm{Cu}(\mathrm{II})$ environment as a very elongated $\mathrm{Cu}\left(\mathrm{N}_{3} \mathrm{Cl}\right)(\mathrm{NCl})$ octahedron (Figure 1). Besides the distorted octahedral environment, this weak $\mathrm{Cu} \cdots \mathrm{Cl}^{(\mathrm{iii})}$ interaction generates chlorido bridges connecting the "Cu-tpbd-Cu" dinuclear units. Thus, the molecular structure of both compounds can be described as chains alternating 1,4-tpbd bridges and double asymmetric $\mathrm{Cl}$ bridges along the $b$-axis (Figure 2). Finally, owing to the weak hydrogen interactions occurring between adjacent chains the overall 
structure can be viewed as weakly connected 3D lattices for both compounds.

The $\mathrm{Cu} \cdots \mathrm{Cu}$ distance across the bis-chelating organic ligand (8.194(1) $\AA$ for $\mathbf{1}$ and $8.245(3) \AA$ for 2$)$ is in the range of the corresponding distances observed for parent complexes involving similar " $\mathrm{Cu}$ tpbd-Cu" bridges [14,18-19]; and, as expected, the $\mathrm{Cu} \cdots \mathrm{Cu}$ distance through the asymmetrical $\left(\mu_{2^{-}}\right.$ $\mathrm{Cl})_{2}$ bridges is significantly shorter (4.021(2) $\AA$ for $\mathbf{1}, 4.125(2) \AA$ for 2 ).

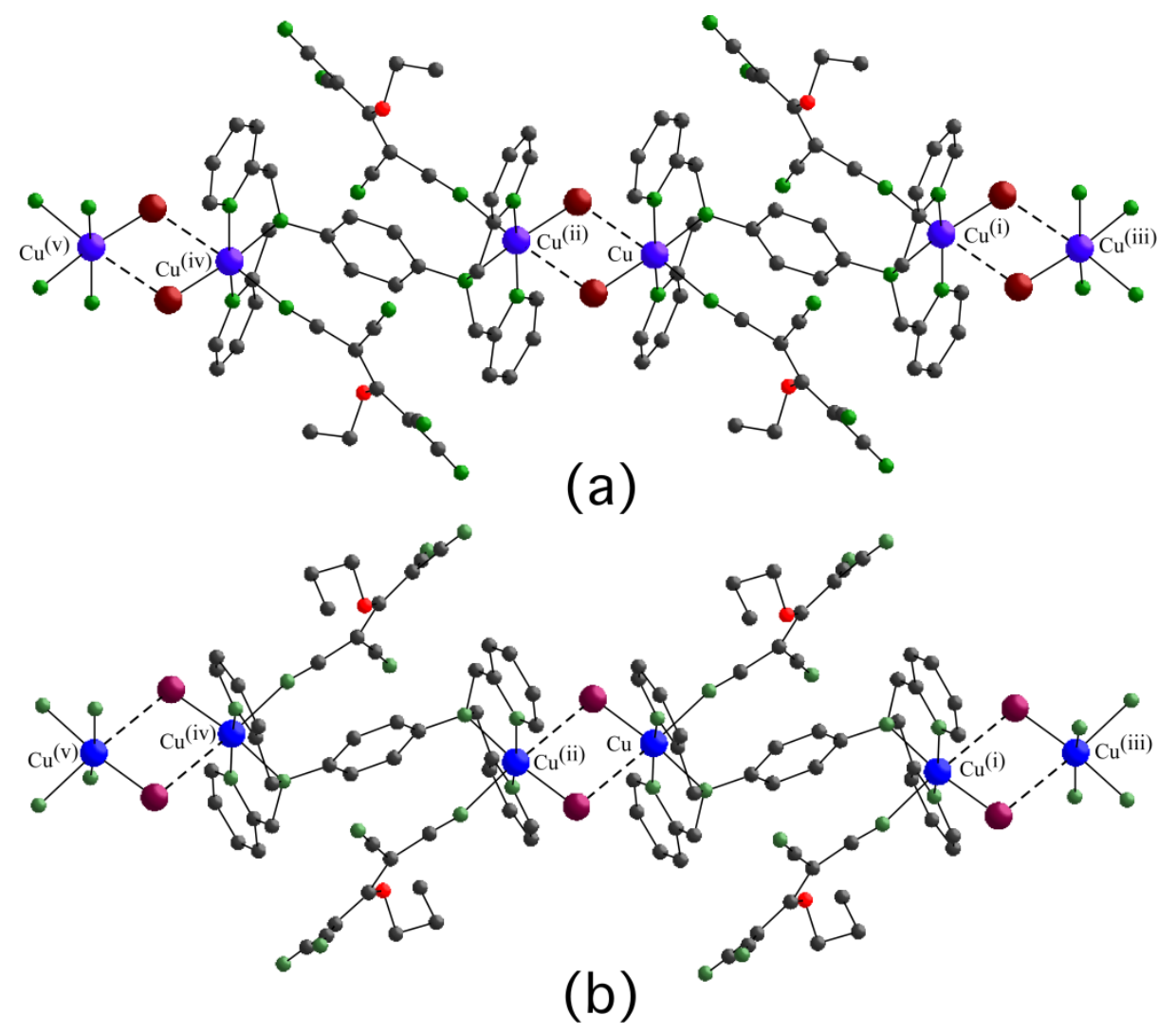

Figure 2. View of the chain structure of 1 (a) and $\mathbf{2}$ (b) along the [010] direction showing the bischelating coordination mode of the 1,4-tpbd organic ligand and the double asymmetric $\mathrm{Cl}$ bridges. Code of equivalent positions: (i) 1-x, 1-y, 1-z; (ii) $1-\mathrm{x},-\mathrm{y}, 1-\mathrm{z}$; (iii) $\mathrm{x}, 1+\mathrm{y}, \mathrm{z}$; (iv) $\mathrm{x},-1+\mathrm{y}, \mathrm{z}$; (v) 1-x, -1-y, $1-\mathrm{z}$.

A careful examination of the reported copper (II) complexes involving double $\mu$-dichlorido bridges and a distorted octahedral coordination geometry, reveals that they all display discrete dinuclear structures and asymmetrical bridges characterized by two different $\mathrm{Cu}-\mathrm{Cl}$ distances [2835]. The shortest distance corresponds to a normal $\mathrm{Cu}-\mathrm{Cl}$ bond length and does not show any significant variation from complex to complex (2.218-2.278 $\mathrm{A}$ ); while the longest one shows a large deviation (2.698-3.112 $\AA$ ). It is worthy to note that this difference becomes more marked in complexes 1 and 2 (3.175(1) $\AA$ for 1 ; 3.293(2) $\AA$ for 2). This may be explained by the steric hindrance imposed by the bulky organocyanide anions in both compounds.

It is worth to note that the 1,4-tpbd organic ligand acting with its regular bis-chelating mode, 
can adopt a cis or a trans conformation as observed in several complexes involving M-tpbd-M dinuclear units (Scheme 2). Complexes 1 and 2 (see Figure 1) present the trans conformation that minimizes the steric hindrance and is the most commonly observed in the reported complexes involving the bis-chelating coordination mode of this ligand.

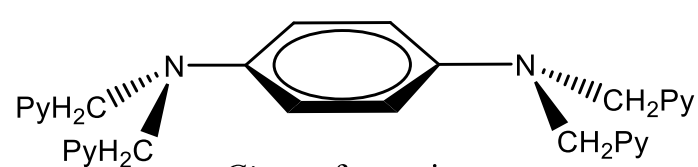

Cis conformation

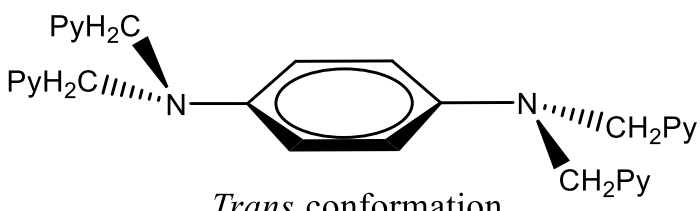

Scheme 2. The Cis and Trans conformations observed for the bis-chelating 1,4-tpbd ligand.

In addition, in the metal ion coordination sphere, the two tridentate moieties of the 1,4-tpbd ligand can act in either mer or fac configuration (Scheme 3) depending of the geometrical constraints of the involved ligands. In the case of $\mathbf{1}$ and $\mathbf{2}$, the pyridine rings display a mer arrangement with respect to the metal ion as established by the N2-Cu-N3 angle values, 161.54(9) ${ }^{\circ}$ for 1 and $161.3(2)^{\circ}$ for 2. This mer coordination may be favoured by the presence of the bulky terminal organocyanide anions.
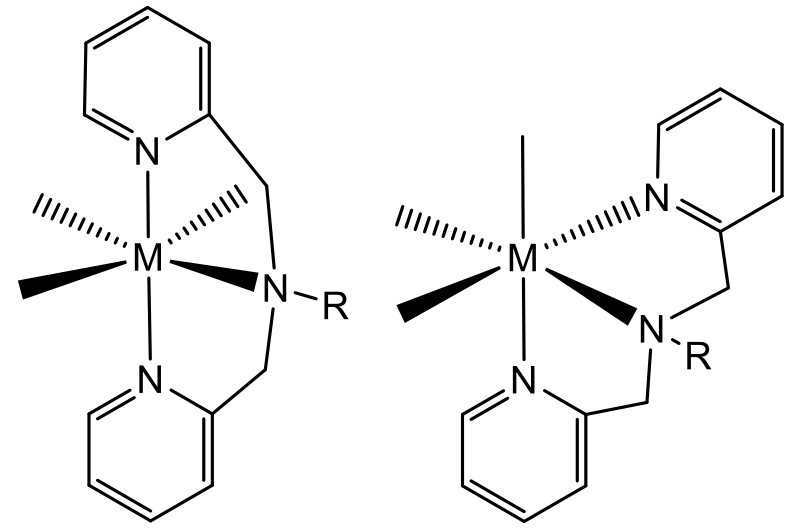

Scheme 3. mer (left) and fac (right) coordination modes of the pyridine groups in the 1,4-tpbd ligand

Finally we can conclude that despite the rigidity of the central fragment of the 1,4-tpbd ligand, the presence of the two flexible " $\mathrm{N}\left(\mathrm{CH}_{2}-\mathrm{Py}\right)_{2}$ " coordinating groups make the 1,4-tpbd a versatile ligand for the design of original coordination polymers with a large structural diversity.

Compounds 1 and 2 display very similar magnetic behaviors (Figures 3 and 4). The product of the molar magnetic susceptibility per $\mathrm{Cu}(\mathrm{II})$ dimer times the temperature, $\chi_{\mathrm{m}} \mathrm{T}$, shows a value at room temperature of $c a .0 .8 \mathrm{~cm}^{3} \mathrm{~K} \mathrm{~mol}^{-1}$ for both compounds, the expected value for two isolated $\mathrm{S}=1 / 2$ 
$\mathrm{Cu}(\mathrm{II})$ ions. When the temperature is decreased, $\chi_{\mathrm{m}} \mathrm{T}$ shows a continuous decrease that becomes more abrupt below ca. $60 \mathrm{~K}$ and reaches values close to zero at $2 \mathrm{~K}$. This behavior suggests the presence of moderate antiferromagnetic $\mathrm{Cu} \cdots \mathrm{Cu}$ interactions in both compounds, as confirmed by the maxima observed at $c a .50 \mathrm{~K}$ in the thermal variation of $\chi_{\mathrm{m}}$ in both compounds. At very low temperatures both compounds show a divergence of $\chi_{\mathrm{m}}$ indicating the presence of a small amount of paramagnetic impurities probably due to the presence of crystal defects and vacancies that give rise to monomeric paramagnetic $\mathrm{Cu}(\mathrm{II})$ species.

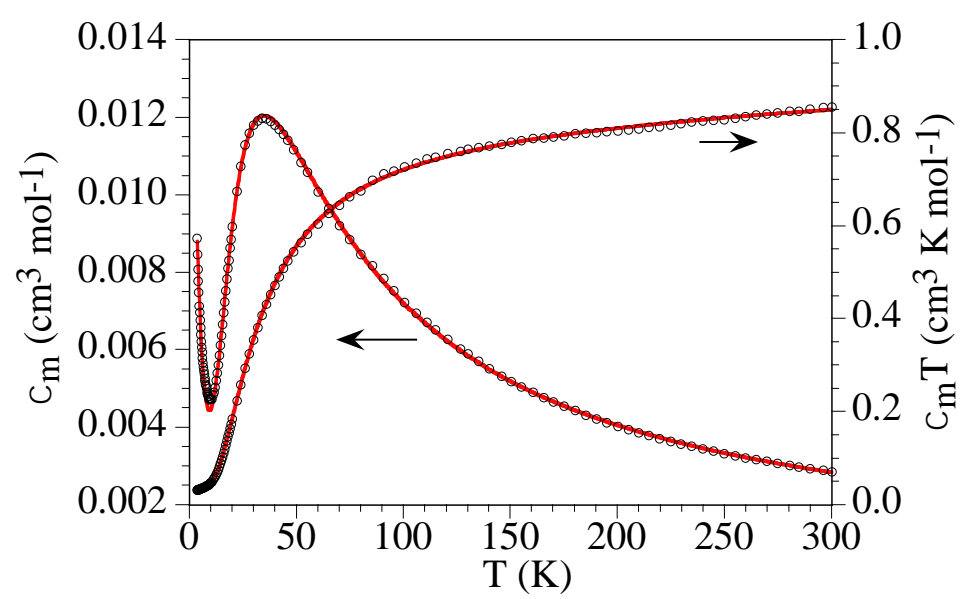

Figure 3. Thermal dependence of $\chi_{\mathrm{m}}$ (left scale) and $\chi_{\mathrm{m}} \mathrm{T}$ (right scale) for compound 1. Solid lines are the best to the model (see text).

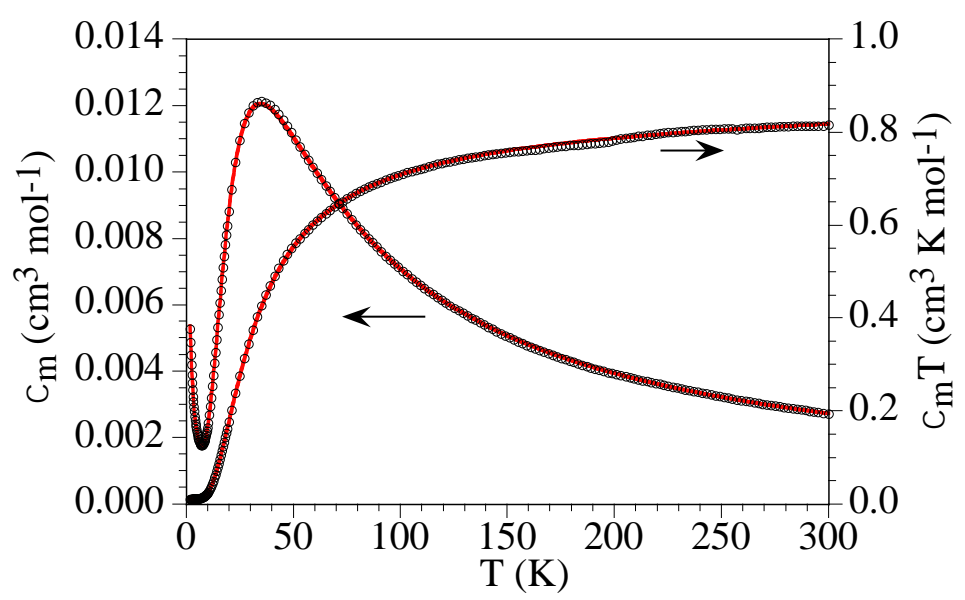

Figure 4. Thermal dependence of $\chi_{\mathrm{m}}$ (left scale) and $\chi_{\mathrm{m}} \mathrm{T}$ (right scale) for compound 2. Solid lines are the best to the model (see text).

Given the alternating chain structure displayed by both compounds, we can consider, in a first approach, two possible models to fit the magnetic properties: (i) an alternating $S=1 / 2$ chain model or (ii) a simple $S=1 / 2$ dimer model if one of the exchange pathways is negligible compared with the other. A detailed analysis of the literature shows that the asymmetric double chlorido bridges always give rise to very weak antiferromagnetic couplings lower than $0.2 \mathrm{~cm}^{-1}$. In contrast the few examples 
of dinuclear $\mathrm{Cu}(\mathrm{II})$ complexes with 1,4-tpbd bridges present moderate antiferromagnetic exchange interactions as in $\left[\mathrm{Cu}_{2}(1,4-\mathrm{tpbd})\left(\mathrm{H}_{2} \mathrm{O}\right)_{4}\right]\left(\mathrm{S}_{2} \mathrm{O}_{6}\right)$ (3) [14] and $\left[\mathrm{Cu}_{2}(1,4-\mathrm{tpbd})\left(\mathrm{H}_{2} \mathrm{O}\right)_{4}\right]\left(\mathrm{ClO}_{4}\right)_{4}(4)$ [18] that show coupling constants of -15.6 and $-26.6 \mathrm{~cm}^{-1}$, respectively. The only exception is compound $\left[\mathrm{Cu}\left(\mathrm{H}_{2} \mathrm{O}\right)(\text { phen })\right\}_{2}(1,4-$ tpbd $\left.)\right]\left(\mathrm{ClO}_{4}\right)_{4},(5)$ that shows a negligible antiferromagnetic exchange due to geometric factors [36] (see below). These results show that the magnetic coupling through the 1,4tpbd bridge in 1 and $\mathbf{2}$ must be $c a$. 100 times higher than that through the double asymmetric chlorido bridge and, therefore, we can neglect this latter bridge and consider compounds $\mathbf{1}$ and $\mathbf{2}$ as simple $\mathrm{Cu}$ (II) dimers connected through 1,4-tpbd bridges. Accordingly, we have used the classical BleaneyBowers $S=1 / 2$ dimer model to fit the magnetic properties of both compounds [37]. In order to reproduce the Curie-tail at very low temperatures observed in the $\chi_{\mathrm{m}} v s$. T plot, we have included a paramagnetic $S=1 / 2$ impurity. This model reproduces very satisfactorily the magnetic properties of the two compounds in the whole temperature range, with the following parameters: $\mathrm{g}=2.114$, $\mathrm{J}=-41.2 \mathrm{~cm}^{-1}$ and $\rho=4.1 \%$ for compound $\mathbf{1}$ (solid lines in figure 3, the hamiltonian is written as $\mathrm{H}=-\mathrm{JS}_{1} \mathrm{~S}_{2}$ ); and $\mathrm{g}=2.105, \mathrm{~J}=-39.3 \mathrm{~cm}^{-1}$ and $\rho=1.3 \%$ for compound 2 (solid lines in figure 4).

Since compounds 1 and 2 represent the fourth and fifth examples of $\mathrm{Cu}$ (II) dimers connected through a 1,4-tpbd bridge, it is not possible to establish any magneto-structural correlation. Albeit, we can, in principle, distinguish two possible situations: on one side compound $\left[\mathrm{Cu}\left(\mathrm{H}_{2} \mathrm{O}\right)(\text { phen })\right\}_{2}(1,4$-tpbd) $]\left(\mathrm{ClO}_{4}\right)_{4}$ (5) [36], that presents a negligible coupling and on the other side, the four remaining compounds: $\left[\mathrm{Cu}_{2}(1,4-\mathrm{tpbd})\left(\mathrm{H}_{2} \mathrm{O}\right)_{4}\right]\left(\mathrm{S}_{2} \mathrm{O}_{6}\right) \quad(3) \quad[14], \quad\left[\mathrm{Cu}_{2}(1,4-\right.$ tpbd) $\left.\left(\mathrm{H}_{2} \mathrm{O}\right)_{4}\right]\left(\mathrm{ClO}_{4}\right)_{4}$ (4) [18] and compounds $\mathbf{1}$ and 2, that present moderate antiferromagnetic couplings in the range -15.6 to $-41.2 \mathrm{~cm}^{-1}$. If we analyze the structural features of these compounds, we can see that in compound 5 the amine $\mathrm{N}$ atom of the 1,4-tpbd occupies an axial position of an elongated octahedron around the $\mathrm{Cu}(\mathrm{II})$ atom, resulting in a negligible orbital overlap (since the magnetic orbital is located on the equatorial plane). In contrast, in compounds 1-4 the amine $\mathrm{N}$ atom occupies always an equatorial position (of elongated octahedron in $\mathbf{1}$ and $\mathbf{2}$, of a square plane in $\mathbf{3}$ and of a square pyramid in 4). This geometry favors the orbital overlap between the $\mathrm{Cu}(\mathrm{II})$ ions and the central aromatic ring, giving rise to a moderate antiferromagnetic coupling, as observed in compounds 1-4. This moderate antiferromagnetic coupling results from the spin polarization mechanism along the N-Ph-N bridge connecting both $\mathrm{Cu}$ (II) ions (scheme 4). This situation is due to

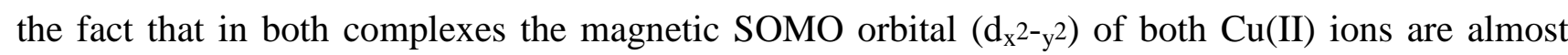
perpendicular to the phenylenediamine plane, leading to a direct overlap of the $d_{x^{2}-y^{2}}$ orbital and the $\pi$ cloud of the pyridyl ring. As a result of this overlap, the magnetic coupling is controlled by the spin polarization mechanism resulting in the prevalence of the well known alternation spin rule that leads 
to an antiparallel alignment of the spins on the $\mathrm{Cu}(\mathrm{II})$ ions (scheme 4).

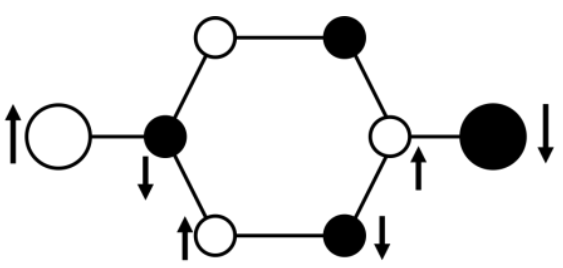

Scheme 4. Spin density distribution in the 1,4-phenylenediamine bridging ligand in $\mathrm{Cu}(\mathrm{II})$ dimers

Interestingly, the $\mathbf{J}$ values found in $\mathbf{1}$ and $\mathbf{2}\left(-41.2\right.$ and $-39.3 \mathrm{~cm}^{-1}$, respectively) are very similar to those observed in several closely related $\mathrm{Cu}(\mathrm{II})$ dimers with 1,4-phenylenediamine bridges where similar magnetic couplings, in the range -35.2 to $-70.2 \mathrm{~cm}^{-1}$, have been found [38,39]. Finally, in order to explain the larger values of $|\mathrm{J}|$ found in $\mathbf{1}$ and $\mathbf{2}\left(-41.2\right.$ and $-39.3 \mathrm{~cm}^{-1}$, respectively) compared with 3 and 4 (-15.6 and $-26.6 \mathrm{~cm}^{-1}$, respectively) we can use the magneto-structural correlation established between the $\mathrm{J}$ value and the $\mathrm{Cu}-\mathrm{N}-\mathrm{C}-\mathrm{C}$ torsion angle $(\phi)$. Although this correlation uses only two points, it clearly shows that the value of $|\mathrm{J}|$ increases as the $\phi$ angle increases [38]. With this correlation, we can deduce that the $\mathrm{J}$ values for compounds $\mathbf{1}$ and $\mathbf{2}$ (with $\phi$ values of $85.4^{\circ}$ in $\mathbf{1}$ and $84.7^{\circ}$ in 2) should be close to -45 and $-44 \mathrm{~cm}^{-1}$, respectively, in agreement with the experimental values (-41.2 and $-39.3 \mathrm{~cm}^{-1}$, respectively) and close to the one observed in the 1,4-phenylenediamine bridged complex $\left[\mathrm{Cu}_{2}(\text { tren })_{2}(\mathrm{ppda})\right]\left(\mathrm{ClO}_{4}\right)_{4} \cdot 2 \mathrm{H}_{2} \mathrm{O}(\mathbf{6})$, where $\phi=80.9$ and $86.5^{\circ}$ and $\mathrm{J}=-51.4 \mathrm{~cm}^{-1}$ [38]. On the other hand, the $\phi$ values observed for 3 and $4\left(53.2^{\circ}\right.$ and $66.2^{\circ}$, respectively) $[14,18]$ lead to lower $\mathrm{J}$ values (in absolute terms) of ca. -16 and $-25 \mathrm{~cm}^{-1}$, respectively, also in good agreement with the experimental values (-15.6 and $-26.6 \mathrm{~cm}^{-1}$, respectively). The inclusion of these three complexes presenting a similar conformation of the 1,4-phenylenediamine bridge $(\mathbf{1}, \mathbf{2}$ and $\mathbf{4}$,) in the magneto-structural correlation confirms the exponential dependence of $\mathrm{J}$ with the angle $\phi$ and results in an improved relationship with $|\mathrm{J}|=3.094 * \exp (0.0314 * \phi)$ (solid line in figure 5). 


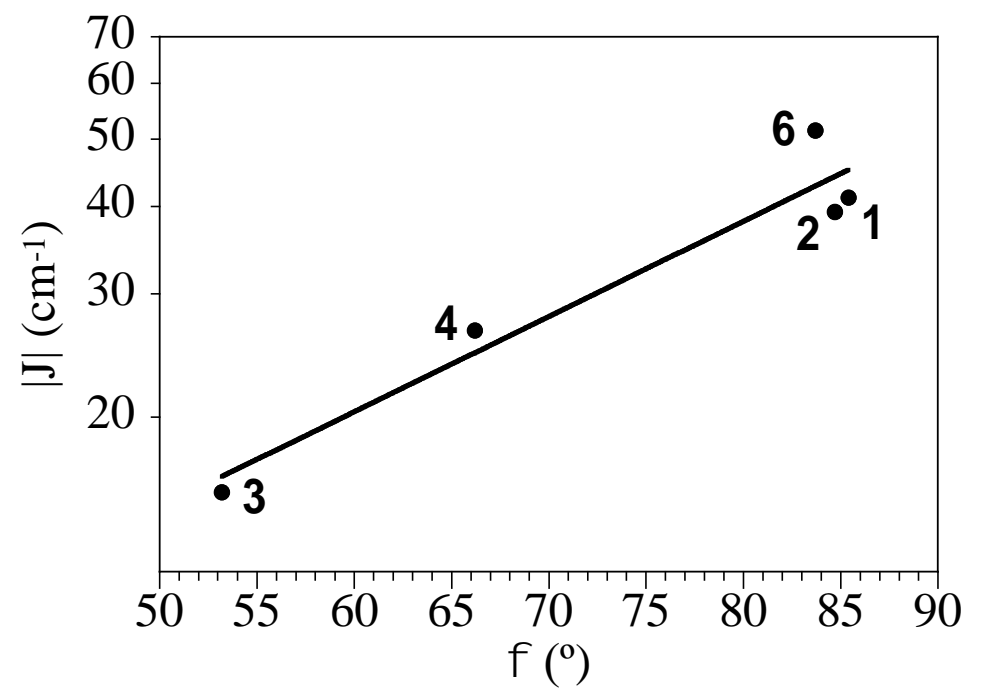

Figure 5. Angular dependence of the magnetic coupling (logarithmic scale) in 1,4-phenylenediamine bridged $\mathrm{Cu}(\mathrm{II})$ complexes. Solid line is the best fit to an exponential law (see text).

\section{Conclusions}

In this paper we have reported the structural characterization and the magnetic properties of two copper coordination polymers based on the 1,4-tpbd ligand and two cyanocarbanion ligands (tcnoet) and (tcnopr) $)^{-}$Both exhibit very close molecular structures which can be described as zigzag chains alternating $\mathrm{Cu}$-tpbd- $\mathrm{Cu}$ and asymmetric double chlorido bridges. For both complexes, the magnetic properties show antiferromagnetic exchange interactions, taking place through the 1,4-tpbd bridge (since the double asymmetric chlorido bridge gives always a negligible coupling). The magnetic data were fitted using a simple $S=1 / 2$ dimer model and the presence of a moderate antiferromagnetic coupling has been rationalized from the coordination geometry for compounds $\mathbf{1}$ and $\mathbf{2}$ as well as for the three other similar reported $\mathrm{Cu}$ (II) dimers with a 1,4-tpbd bridge. Furthermore, these compounds have confirmed the magneto-structural correlation between $\mathrm{J}$ and the torsion $\mathrm{Cu}-\mathrm{N}-\mathrm{C}-\mathrm{C}$ angle $(\phi)$, previously established with only two examples.

\section{Supplementary material}

Electronic Supplementary Information (ESI) available: This material is available free of charge via the Internet. CCDC 1042474 and 1042475 ( $\mathbf{1}$ and $\mathbf{2}$, respectively) contains the supplementary crystallographic data for this paper. These data can be obtained free of charge from The Cambridge Crystallographic Data Centre via www.ccdc.cam.ac.uk/data_request/cif. See DOI: $10.1039 / \mathrm{b} 000000 x /$ 


\section{Acknowledgments}

We acknowledge the CNRS ("Centre National de la Recherche Scientifique"), the Brest University, the "Agence Nationale de la Recherche" (ANR project BISTA-MAT: ANR-12-BS07-0030-01), the French "Ministère de la Recherche et Ministère des Affaires Etrangères et Européennes (PHC MAGHREB Project $N^{\circ}$ 30255ZJ)", the Spanish MINECO (Project CTQ2011-26507), and the Generalitat Valenciana (projects Prometeo II/2014/076 and ISIC). Authors especially thank the "Service Commun" of NMR facilities of the University of Brest. 


\section{References}

[1] S. Triki, J. Sala Pala, M. Decoster, P. Molinié, L. Toupet, Angew. Chem. Int. Ed. 38 (1999) 113-115.

[2] F. Thétiot, S. Triki, J. Sala Pala, C. J. Gómez-García, J. Chem. Soc, Dalton Trans. (2002) 16871693.

[3] F. Thétiot, S. Triki, J. Sala Pala, Polyhedron 22 (2003) 1837-1843.

[4] S. Benmansour, F. Setifi, S. Triki, J.-Y. Salaün, F. Vandevelde, J. Sala-Pala, C. J. GómezGarcía, T. Roisnel, Eur. J. Inorg. Chem. (2007) 186-194

[5] C. Atmani, F. Setifi, S. Benmansour, S. Triki, M. Marchivie, J.-Y. Salaün, C. J. Gómez-García, Inorg. Chem. Commun. 11 (2008) 921-924.

[6] S. Benmansour, F. Setifi, S. Triki, C. J. Gómez-García, Inorg. Chem. 2012, 51, 2359-2365.

[7] S. Triki, F. Thétiot, J.-R. Galán-Mascarós, J. Sala Pala, K. R. Dunbar, New J. Chem. 25 (2001) 954-958.

[8] F. Thétiot, S. Triki, J. Sala Pala, J.-R. Galan-Mascaros, J. M. Martínez-Agudo, K. R. Dunbar, Eur. J. Inorg. Chem. 2004, 3783-3791.

[9] S. Triki, F. Thétiot, F. Vandevelde, J Sala-Pala, C. J. Gómez-García, Inorg. Chem. 44 (2005) 4086-4093.

[10] G. Dupouy, M. Marchivie, S. Triki, J. Sala-Pala, J.-Y. Salaün, C. J. Gómez-García, P. Guionneau, Inorg. Chem. 47 (2008) 8921-8931.

[11] G. Dupouy, M. Marchivie, S. Triki, J. Sala-Pala, C. J. Gomez-Garcia, S. Pillet, C. Lecomte, J.F. Létard, Chem. Commun. (2009) 3404-3406.

[12] G. Dupouy, S. Triki, M. Marchivie, N. Cosquer, C. J. Gómez-García, S. Pillet, E.-E. Bendeif, C. Lecomte, S. Asthana, J.-F. Létard, Inorg. Chem. 49 (2010) 9358-9368.

[13] F. Setifi, S. Benmansour, M. Marchivie, G. Dupouy, S. Triki, J. Sala-Pala, J.-Y. Salaün, C. J. Gómez-García, S. Pillet, C. Lecomte, E. Ruiz, Inorg. Chem. 48 (2009) 1269-1271.

[14] T. Buchen, A. Hazell, L. Jessen, C. J. McKenzie, L. P. Nielsen, J. Z. Pedersen, D. Schollmeyer, J. Chem. Soc. Dalton Trans. (1997) 2697-2704.

[15] A. Hazell, C.J. McKenzie, L.P. Nielsen, Polyhedron 19 (2000) 1333-1338.

[16] A. Hazell, R. Hazell, C.J. McKenzie, L.P. Nielsen, Dalton Trans. (2003) 2203-2208.

[17] A. Hazell, C.J. McKenzie, L.P. Nielsen, J. Chem. Soc. Dalton Trans. (1998) 1751-1756.

[18] D.-D. Li, J. Tian, Y Kou, F. Huang, G. Chen, W. Gu, X. Liu, D. Liao, P. Cheng, S. Yan, Dalton Trans. (2009) 3574-3583. 
[19] D.-D. Li, J.-L. Tian, W. Gu, X. Liu, H.-H. Zeng, S.-P. Yan, J. Inorg. Biochem. 105 (2011) 894901.

[20] G. A. Bain and J. F. Berry, J. Chem. Educ. 85 (2008) 532-536.

[21] CRYSALIS-CCD 170, Oxford-Diffraction, 2002; CRYSALIS-RED 170, Oxford-Diffraction (2002)

[22] M. Sheldrick, SHELX97. Programs for Crystal Structure Analysis, University of Göttingen, Göttingen, Germany (1997).

[23] L.J. Farrugia, J. Appl. Crystallogr. 32 (1999) 837-838.

[24] International tables for X-ray crystallography. Vol. 4, Kynoch Press, Birmingham (1975).

[25] (a) L. J. Farrugia, J. Appl. Cryst. 30 (1997) 565-565; (b) L. J. Farrugia, J. Appl. Cryst. 45 (2012) 849-854.

[26] R.J.H. Clark, C.S. Williams, Inorg. Chem. 4 (1965) 350-357.

[27] A.W. Addison, T.N. Rao, J. Reedijk, J. van Rijn, G.C. Verschoor, J. Chem. Soc. Dalton Trans. (1984) 1349-1356

[28] J. Valdes-Martinez, D. Salazar-Mendoza, R. A. Toscano, Acta Crystallogr. Sect. E Struct. Rep. Online 58 (2002) m712-m714.

[29] B. Antonioli, B. Büchner, J. K. Clegg, K. Gloe, K. Gloe, L. Götzke, A. Heine, A. Jäger, K.

A. Jolliffe, O. Kataeva, V. Kataev, R. Klingeler, T. Krause, L. F. Lindoy, A. Popa, W. Seichter, M. Wenzel, Dalton Trans. (2009) 4795-4805.

[30] T. Rojo, M. I. Arriortua, J. Ruiz, J. Darriet, G. Villeneuve, D. Beltran-Porter, J. Chem. Soc. Dalton Trans. (1987) 285-291.

[31] D. Maiti, J. S. Woertink, A. A. Narducci Sarjeant, E. I. Solomon, K. D. Karlin, Inorg. Chem. 47 (2008) 3787-3800.

[32] R. D. Willett, Acta Crystallogr. Sect. E Struct. Rep. Online 57 (2001) m605-m606.

[33] A. Nielsen, C. J. McKenzie, A. D. Bond, Acta Crystallogr. Sect. E Struct. Rep. Online 62 (2006) m2453-m2454.

[34] M. El Kodadi, M. Fouad, A. Ramdani, D. Eddike, M. Tillard, C. Belin, Acta Crystallogr. Sect. E Struct. Rep. Online 60 (2004) m426-m428.

[35] A. Nielsen, C. J. McKenzie, A. D. Bond, Acta Crystallogr. Sect. E Struct. Rep. Online 62 (2006) $\mathrm{m} 2455-\mathrm{m} 2456$.

[36] F. Reuter, E. Rentschler, Polyhedron 52 (2013) 788-796.

[37] B. Bleaney, K. D. Bowers, Proc. R. Soc. Lond. A. 214 (1952) 451-465. 
[38] C. Yuste, J. Ferrando-Soria, D. Cangussu, O. Fabelo, C. Ruiz-Pérez, N. Marino, G. De Munno, S. E. Stiriba, R. Ruiz-García, J. Cano, F. Lloret, M. Julve, Inorg. Chim. Acta 363 (2010) 19841994.

[39] T. R. Felthouse, D. N. Hendrickson, Inorg. Chem. 17 (1978) 2636-2648] 